\title{
Description and New Recorder to Species belong to Genus Acrida Linnaeus, 1758 sp. nov. (Orthopetra:Acridiane) from Baghdad Province, Iraq
}

\author{
Rawa' J. H. Al-Kaissy
}

\begin{abstract}
The morphological appearance of Acrida Linnaeus, 1758 sp. nov. of order Orthopetra, where the classification location of this genus was defined with its charactrestics, as well as its prevalence with a description of the characteristics of the morphological appearance of the body, head, antenne, both pronotum and mesothorax, the fore and hind wings, the posterior leg, as well as the male genitalia with the most important characteristics of staining, veins and variations in appearance.
\end{abstract}

\section{Keywords - Orthoptera, Acridiade, Acridinae, Acrida}

\section{INTRODUCTION}

Orthoptera, Latreille, 1793 order is one of the most widespread and complex orders in the environment because of its economic role, it tends to all green plants and includes this order approximately 20,000 species, and may reach 22.50 species, thus representing $10 \%$ of the total species scattered in insects which it is estimated at 1,750 species and this order includes two sub-order: Caelifera (Short-horned) Grasshopper, Ensifera (Long-horned) Grasshopper [1]. Acrididae family is known by short horned Grasshopper, where its members are characterized by antenne that are usually shorter than the body, as ovipositor are short as well, their members are known for the heterogeneity in behavior and colors where some move collectively, while others move to live alone [2]. This family comprises about 8,000 species, including 40 species spread across Africa, Europe, Asia, East Asia, the United Kingdom, Saudi Arabia, Iran, Turkey [3. 4] where they are considered dangerous to agricultural crops [5]. Calssification position of Acrida, Linnaeus, 1758 genus

Order: Orthoptera

Supe Family: Acridoidae

Sub Falimy: Acridinae

Trib: Acridini, Macleay, 1821

Genus: Acrida (Linnaeus, 1758) [6]

Diagnostic characteristics of Acridinae sub-family

1. The head is very sharp and has a sharp angle, especially at the front.

2. The veins of fore wing are unclear and if found they are weak.

3. The body is small to large, long, the head is slanted from the axis of the body long, the lack of stridulatory.

Rawa' J. H. Al-Kaissy, Department of Bilgy, College of Education for Pure Science (Ibn Al-Haitham), University of Baghdad, Baghdad, Iraq..
4. Lack of intercalary vein in fore wing [5; 7].

Characteristics of Acrida (Linnaeus, 1758) genus

- The body is medium-sized to large, prolonged.

- Dagger-shaped antenne are roughly equal to or shorter than the head, and pronotum is combined.

- The vertex cap is stretched.

- The pronotum is long.

- Full-grown fore wings reach the end of the abdomen [7].

\section{MAterials AND MethodS}

The samples, which include 20 from the Baghdad area in the fourth month of 2017, were collected using sweep net, as well as the use of the hand during the collection, where they were killed using ethyl alcohol, and then stored in special boxes after using pins to install them [5]. The information on the collection were added including date, location of collection and host plant, if found, then the samples were diagnosed using diagnostic keys and then separated the parts successively from the head, thorax, legs, wings and abdomen, using the anatomical microscope and description of each part sequentially and photographed using a microscope and Lucida camera $[8,9]$.

\section{RESULTS}

Body: Prolonged, general earthy color with several green spots on fore wings, total length $9.8-1 \mathrm{~cm}$. (Fig.1).

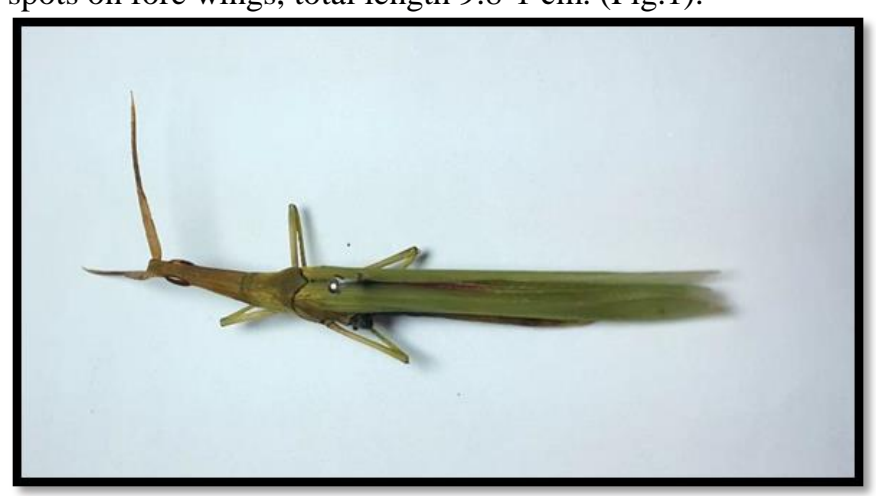

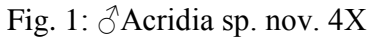

Head: Imperceptitis, skinny, like-for-snake, one-time longer pronotum, compound eye (CO) is very long, thin, brown (Fig 2 $\mathrm{A}, \mathrm{B})$, antenne dagger-base and begins to narrow towards the top (Fig. 2, C).

Vertex: Long, earthy with two yellow lines along the leg behind the compound eyes, Fs stretched almost equal to its 
width, compound eyes (CO) are very long and thin and brown (Fig. 2 A).

Pronotum: Green with several spots in the shape of yellow lines and brown extending along the top of it as well as the sides, the anterior margin is slightly convex the posterior margin P.M. very sharp (Fig. 2 A). Mdc middle carina: Tight from the anterior margin to the posterior margin, Ltc lateral carina is also clear and extends along the lateral margin (L.M.).

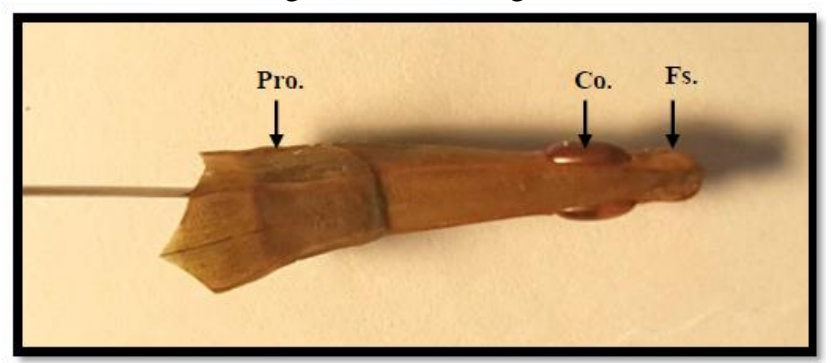

A- Head and pronotum (dorsal view) 10X

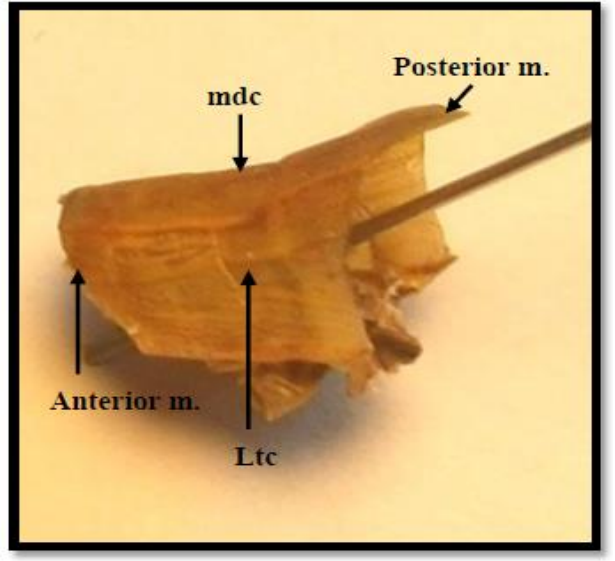

B- Pronotum lateral veiw $10 \mathrm{X}$

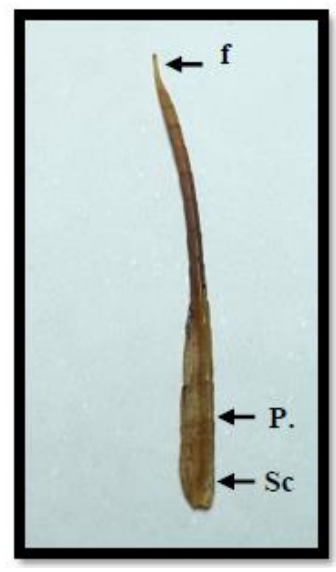

C-Antenne dorsal view $10 \mathrm{X}$

Fig. 2 Head and antenne
Mesostemum: is a general earthy color with several spots with white and brown pits occupying the top of it. The middle vein lobes (Mosi) are half-circled and the distance between them (Mosi) is present and narrow like the letter V and Mstp pit was observed (Fig. 3).

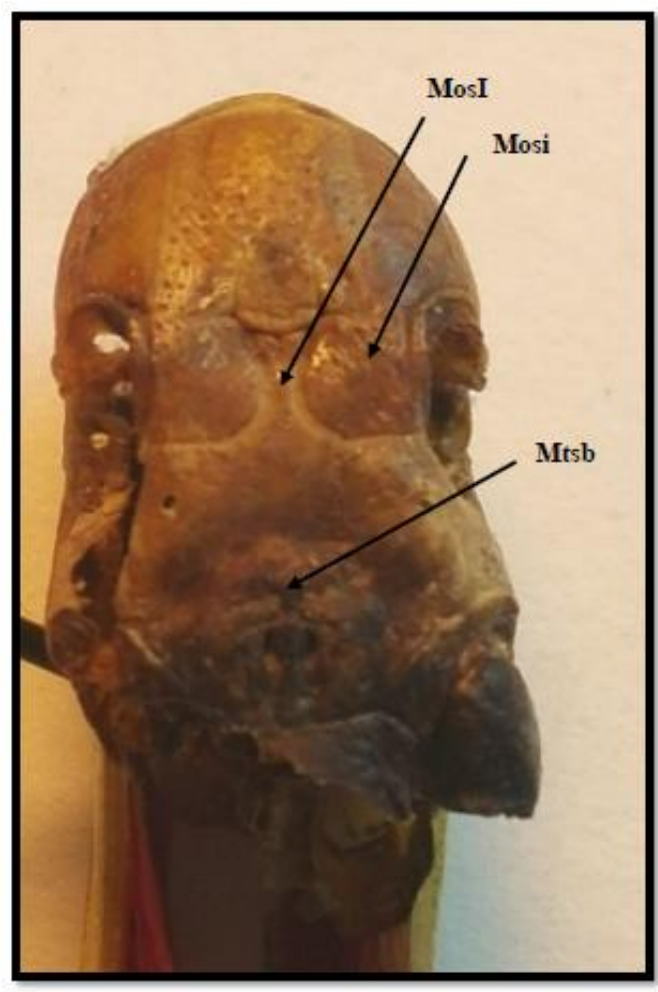

Fig. 3: Mesosternal 10X

Fore wing: Long, skinny, narrow green leather, sharp apical margin that goes beyond the hind wing with somewhat irregular brown spots. Costa margin is almost flat with a brown line along it, as well as the inner margin, narrow veins and noticed sub-costal vein $(\mathrm{Sc})$ as well as mid vein $(\mathrm{M})$ is observed, with frequent trans veins, especially at the top and being cell-like (Fig. 4).

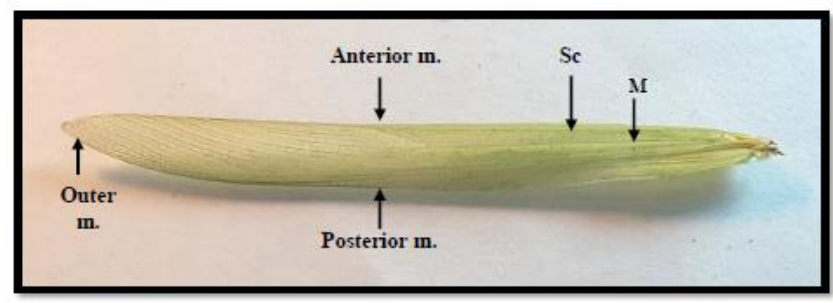

Fig. 4: Mesonotum 10X

Hand wing: Fan-like membrane, pale yellow with pink spots occupying the base part of it, the transverse veins are brown, and the longitudinal veins are dense and clear brown (Fig. 5). 


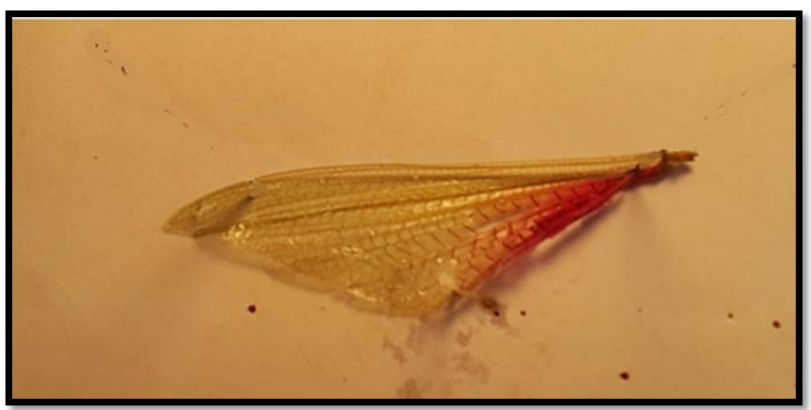

Fig. 5: Hind wing $4 \mathrm{X}$

Hind leg: graceful lye, general earthy color with white stripes, coxa triangular slain. Trochantor: Short, femara long and slim with a pair of small spines at the top and another randomly and gracefully distributed. Tibia lean lye with a row of seven inner spines and an outer spot. Tarsus three pieces, the first piece twice longer than the second piece, the third piece is small, ending with a pair of claws (Fig 6).

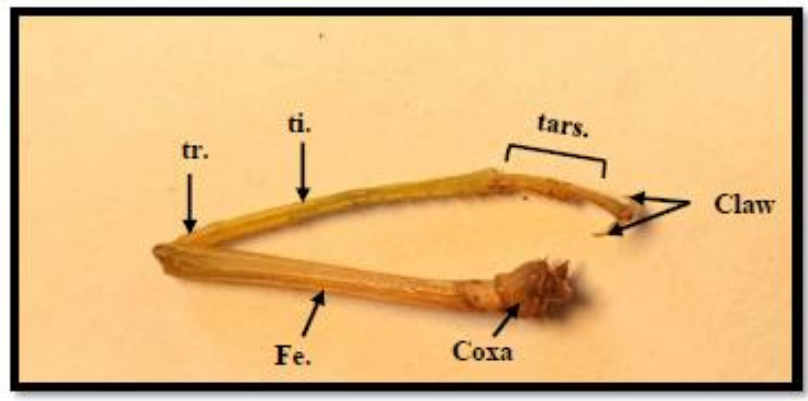

Fig. 6: Leg 4X

\section{Male genitalia}

The penis is not long and sharp and is surrounded by pallium and epiphllus has two protrusions that look like a handle. Anal cerci coneular have a sharp peak which is shorter than the anal plate, sub-genital plate is cone slightly extended (Fig. 7). Epiphallus is a plate on he top of the genital complex, like $\mathrm{H}$ letter and longated with stright end (Fig. 7 A).

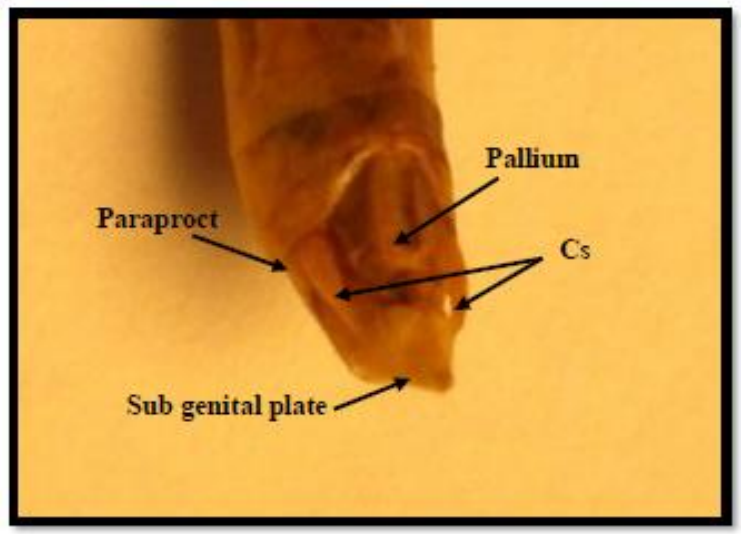

A- Abdominal end of male $\hat{\delta}$

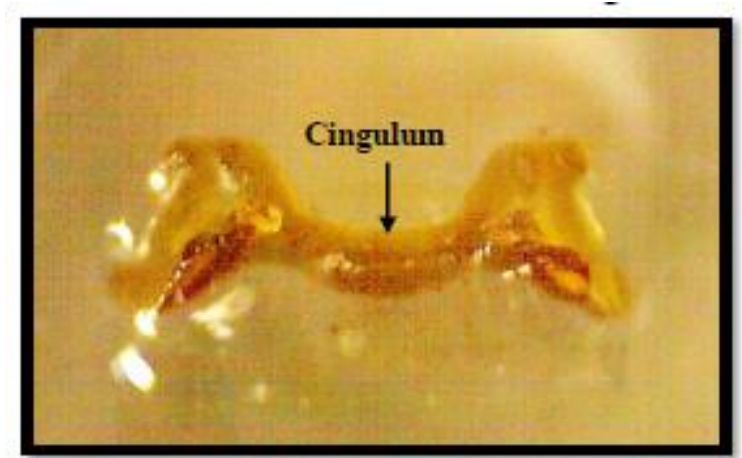

B- Epiphallus

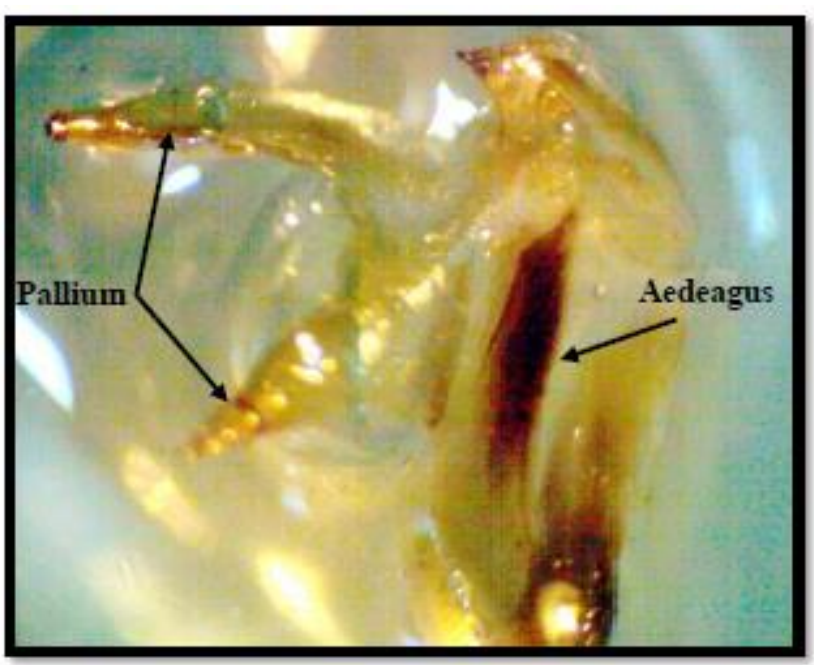

C- Penis

Fig. 7: Male genitalia 10X

This species Acrida sp. nov. similar to Acrida exaltata Wolker, 1859 but different from the following: the head is conical, the base part is narrow and is the length of the pronotum, the pronotoidisc is weak, the wing has an unpointed apex and is like a roof and it has several cells clustered with each other near its base like cloudy, femara is smaller than tegmina $[3,5]$. Vertex is firmly arched, dark and its anterior margin is a little round and prominent forward with a yellow irregular spots, posterior margin is heavily convex, the posterior lateral angle is round.

\section{REFERENCES}

[1] Woller, D.A. \& Song, H. (2017). Investigating the functional morphology of genitalia during copulation in the grasshopper Melanoplus rotundipennis (Scudder, 1878) via correlative microscopy. J. Morphol., 278(3): 334-359. https://doi.org/10.1002/jmor.20642

[2] Kumar, H. \& Usmani, M. K. (2014). Toxonomic studies on Acrididae Orthoptera: Acridoidae, from Rajasthan. J. Entomol. Zool. Stidues, 2(3): 131-146.

[3] Akhtar, M. H. \& Usmani, M. K. (2014). Taxonomic studies on the grasshopper fauna (Orthoptera: Acrididae) recorded from paddy fields in Uttar Pradesh, India. J. Bombay Nat. Hist. Soc., 111(3).

[4] Jabbari, A.; Modarres Awal, M.; Fekrat, L.; Karimi, J. \& Rashki, M. (2015). On the short-horned grasshopper (Orthoptera: Caelifera) fauna of northeastern Iran with some information on sweep sampling capture rates. Iran. J. Animal Biosyst., 11(1): 33-42.

[5] Srinivasan, G. \& Prabaker, D. (2013). A Pictorial Handbook on Grasshoppers of Western Himalayas 2 Zoological survery of India Kolkata., 1-75 September. 
[6] https://en.m.wikipediaorg.wiki,Acrida

[7] Mohammed, H. H. (2016). Taxonomic morphologiral study on some species of short horned grasshopper (Orthoptera: Acrididae) collected from some Iraqi Governorates athesis submitted to the College of Education for pure Science of the University of Tiktit.

[8] Bughio, B.A.; Sultana, R.; Wagan, M. S.; Ullah, F. \& Rafi, M. A. (2013). Studies on the tribe Acrotylini (Acrididae: Orthoptera) from Pakistan. Int. J. Biosci., 3(4): 180-191. https://doi.org/10.12692/ijb/3.4.180-191

[9] Gupta, S. K. \& Chandra, K. (2018). Two new species of slant-faced grasshopper genus Acrida (Acrididae: Acridinae) from India. Halteres, 9: 131-140.

Rawa' J. H. Al-Kaissy (PhD. Lecture, University of Baghdad, Entomology). Qualification: B. Sc. Biology 1995, M. Sc. Biology 2000, PhD. Biology 2016, Scientific Rank: Assistant Lecturer 2001, Instructor 2010, Address: University of Baghdad/ College of Education for pure Science (Ibn Al-Haitham)/ Department of Biology, Courses taught: Entomology and 10 publishing paper. 